\title{
ORIGINAL ARTICLE \\ Sex differences in mania phenotype and ethanol consumption in the lateral hypothalamic kindled rat model
}

\author{
OA Abulseoud ${ }^{1}$, NA Gawad ${ }^{1}$, K Mohamed $^{1}$, C Vadnie $^{2}$, UM Camsari ${ }^{1}$, V Karpyak ${ }^{1}$, MA Frye ${ }^{1}$ and D-S Choi ${ }^{1,2}$
}

\begin{abstract}
Sex differences have been observed in mania phenotypes in humans. However the mechanisms underlying this difference are poorly understood. Activating the lateral hypothalamus is implicated in manic-like behaviors in rodents. Using newly established lateral hypothalamus kindled (LHK) rat mania model, we investigated sex differences of manic-like behaviors and its correlation with voluntary ethanol intake. We stimulated the lateral hypothalamus bilaterally in the male and female Wistar rats over five consecutive days. We recorded and quantified kindling-induced behaviors for each individual animal. We also assessed ethanol consumption using a two-bottle choice ethanol drinking as well as circadian locomotor activity counts daily throughout the experiment. We found notable sex differences in several aspects of manic-like behaviors during kindling. Males exhibited a significantly increased locomotor activity during the light phase, and reduced rest interval. On the other hand, females displayed significantly higher ethanol consumption and more frequent rearing behavior. However, no sex differences were present in the duration of sexual, feeding or grooming behaviors or in dark-phase activity counts. The excessive alcohol intake in LHK female rats is reminiscent of clinically reported sex differences in bipolar patients while the other phenotypic sex differences such as rearing and locomotor activity are less clearly described in clinical studies. Overall, our results lend further evidence for the validity of the LHK rat as a useful model to study brain region-specific molecular changes during mania and its correlation with alcohol use disorders.
\end{abstract}

Translational Psychiatry (2015) 5, e534; doi:10.1038/tp.2015.30; published online 24 March 2015

\section{INTRODUCTION}

Despite equal prevalence rates of mania in men and women, ${ }^{1,2}$ a solid body of literature supports the concept of sex differences. Women with bipolar disorder are more likely to be hospitalized for mania ${ }^{3}$ and have higher rates, in comparison with men of mixed mania, ${ }^{4,5}$ mixed hypomania, ${ }^{6}$ mixed depression ${ }^{7}$ and rapid cycling. ${ }^{8-10}$ Although the prevalence rates for alcohol use disorders comorbidity are higher for bipolar men compared with bipolar women, the odds ratio of risk is significantly higher for bipolar women in comparison with women in the general population. ${ }^{11}$ However, alcohol comorbidity during hospitalization for mania ${ }^{12}$ and self-report measures of maximum drinks per day $^{13}$ have suggested that bipolar women may have alcohol use patterns that meet significant clinical concern. Bipolar manic men, on the other hand, had earlier onset of first-episode mania, ${ }^{14}$ and were more likely than manic women to exhibit hypersexuality ${ }^{15}$ and to report the presence of 'problem behaviors' and excitement. $^{16,17}$

Most of these clinical studies, however, are limited to understand the molecular basis of disease phenotype because of the presence of comorbidities, effects of medications and sometimes the retrospective nature. Using a valid animal model to study these sex differences is a critical step in understanding the neurobiological basis of these differences and to examine the possibility of sex-specific treatment for mania.

The hypothalamus is the brain region that performs the complex task of coordinating various neural systems that mediate different functional responses, ${ }^{18}$ integrating the motivational aspects of behavior with visceral-motor responses, regulating energy homeostasis, ${ }^{19}$ initiating sexual behavior ${ }^{20-23}$ and synchronizing the rhythms of all biological processes with environmental changes to achieve the optimal adaptive response. ${ }^{24}$ The lateral hypothalamic area in particular has been implicated in the processing of sensory information and the expression of behaviors associated with hunger and thirst, aggression, reproduction ${ }^{25}$ and in mediating general arousal and sensory sensitization associated with motivational behavior. ${ }^{26}$

Several lines of evidence suggest the involvement of the hypothalamus in the pathophysiology of mania. Structural brain imaging studies suggest a dilation of the third ventricle in the region where hypothalamic nuclei are located adjacent to its walls, indirectly implicating reduced hypothalamic volume. ${ }^{27-30}$ Furthermore, two postmortem studies ${ }^{31,32}$ showed significant reduction in the volume of the hypothalamic region in patients with bipolar disorder type I compared with those with major depression and healthy controls. Further evidence emerges from neurosurgical case reports of hypothalamic hamartomata where patients with these rare non-neoplastic nodules present with manic-like symptoms described as mood instability, aggressiveness, restlessness and severe rage attacks accompanied by a strange feeling of 'pressure to laugh' called gelastic seizures. ${ }^{33,34}$ On the other hand, preclinical studies in rats, ${ }^{35}$ pigs $^{36}$ and monkeys ${ }^{37}$ have shown that high frequency stimulation of the hypothalamus engages functional circuits involved in different behaviors reminiscent of mania such as hypersexuality, aggression, increased locomotor activity and disturbed sleep-wake cycle. ${ }^{38}$ However, we have specifically employed the kindling paradigm to facilitate spontaneous firing of the lateral hypothalamic neurons

\footnotetext{
1Department of Psychiatry and Psychology, Mayo Clinic, Rochester, MN, USA and ${ }^{2}$ Department of Molecular Pharmacology and Experimental Therapeutics, Mayo Clinic, Rochester, MN, USA. Correspondence: Dr OA Abulseoud or Dr D-S Choi, Department of Psychiatry and Psychology, Mayo Clinic, 200 First Street SW, Rochester, MN 55905, USA. E-mail: osama.abulseoud@nih.gov or choids@mayo.edu
}

Received 1 September 2014; revised 7 January 2015; accepted 20 January 2015 
a

EtoH $20 \%$ v/v two bottle choice and circadian locomotor activity monitoring in home cage

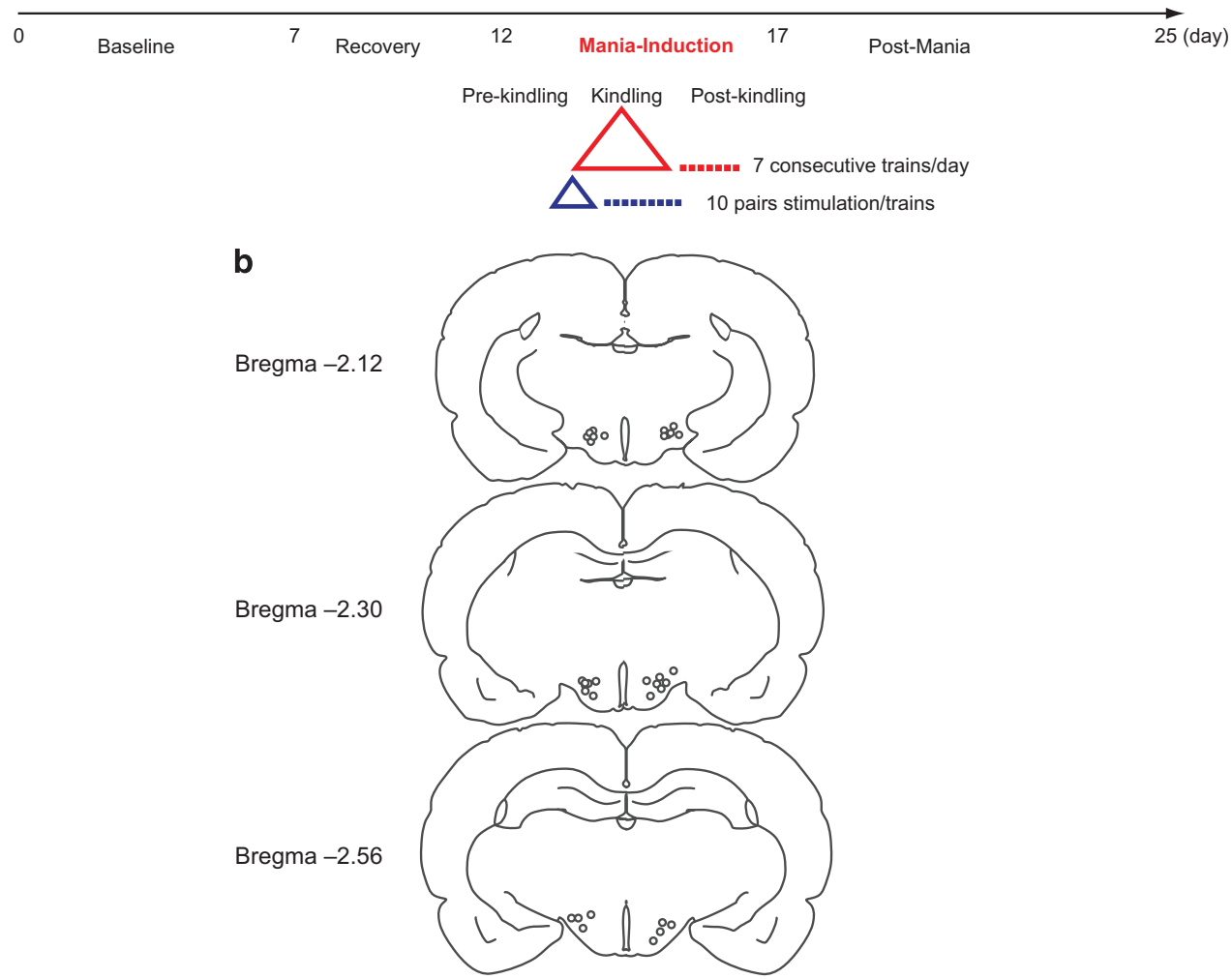

Figure 1. (a) Study design: baseline phase for 7 days, followed by surgical implantation of stimulating electrode and recovery for 5 days before mania induction took place for 5 days. Each day, the animal was allowed an initial pre-kindling habituation period (pre-kindling) for 30 min followed by kindling phase consisting of seven consecutive trains starting at $1 \mathrm{~V}$ for the first train then increased to $2 \mathrm{~V}$ for the subsequent six trains. Two-minute rest intervals were allowed between trains. Each train consisted of 10 pairs of stimulation (10 s) alternating with rest ( $30 \mathrm{~s}$ ). The animal remained in the monitored cage for 30 min during the post-kindling period before it was returned back to home cage for 7 days (post-mania days). Locomotor activity counts and voluntary ethanol (EtOH) consumption were monitored continuously throughout the study period. (b) An illustration of stimulating electrode tip locations plotted within the dorso-medial part of the LHA regions. AP coordinates were between -2.12 to -2.56 from bregma according to Paxinos Atlas. AP, anteroposterior; LHA, lateral hypothalamic area.

and hence induce manic-like behaviors that can carry over during the poststimulation phase of the experiment. Amygdala kindling has been proposed as a model of epilepsy by Post and Weiss ${ }^{39}$ to explain the efficacy of the anticonvulsant carbamazepine in the treatment of mania in patients with bipolar disorder. However, the symptomatology induced by amygdala kindling was distinct from any caused by mania. ${ }^{39}$ Bilateral lateral hypothalamic lesioning, on the other hand, does not lead to manic-like behaviors, rather it causes severe reduction in mobility, food, water intake and body weight. $^{40-42}$ Some of these behaviors could arguably be reminiscent of the depressive phase of bipolar illness. Because either hypo-function of hypothalamus in humans or hyperfunction of hypothalamus of animal models attribute to bipolar disorders, dysregulation of hypothalamus is implicated in bipolar disorders collectively.

We have recently developed a valid rat model for mania through lateral hypothalamic kindling $\left(\right.$ LHK). ${ }^{38}$ Our model displayed significantly increased sexual self-stimulation excessive rearing, feeding and grooming during the kindling interval. Moreover, the LHK male rats also drank more ethanol during the mania-induction days compared with baseline ethanol consumption levels and exhibited increased total locomotor activity with reduced rest interval during the mania-induction and post-mania days compared with baseline activity levels and rest intervals. In addition, chronic administration of lithium or valproic acid significantly attenuated manic-like behaviors in the LHK rat model. ${ }^{38}$ In this study, we focused on sex differences in manic-like behavioral phenotype and voluntary ethanol consumption in rats. Although it is difficult to establish the link between human and rodent behaviors, we have looked at sex differences in feeding behavior in the LHK rat model because binge eating disorder is the most common eating disorder in the United States, with a lifetime prevalence of $\sim 3.5 \%$ in adult women, $2.0 \%$ in adult men. ${ }^{43}$ In addition, a high rate of comorbidity between bipolar disorder and eating disorders has been shown both in community samples and clinical studies. ${ }^{44,45}$ Similarly, we also measured changes in grooming behavior as a putative marker of stress and anxiety ${ }^{46,47}$ for two reasons, first manic episode is a period of intense stress associated with activation of hypothalamic-pituitary-adrenal axis stress hormones, ${ }^{48}$ second, the comorbidity between mania and anxiety disorders is common ${ }^{49}$ specifically among women. ${ }^{50}$

\section{MATERIALS AND METHODS}

All experimental procedures were approved by the Mayo Clinic Institutional Animal Care and Use Committee. In this study, we have used the same methods detailed in our first published mania-induction experiments. ${ }^{38}$ (Figure 1a illustrates the study design).

\section{Animals}

The experiments were done on adult male and female Wistar rats $(n=12$ per group, age 12-16 weeks, weight $250-300 \mathrm{~g}$ at the beginning of experiment) obtained from Charles River Laboratories International (Wilmington, MA, USA). The rats were housed in individual cages on a 
12-h light/dark cycle (lights on at $0600 \mathrm{~h}$ ), free supply of food (ad libitum) and tap water.

\section{Surgical implantation of stimulating electrodes}

Anesthetized animals (isoflurane inhalation: 3.0\% during induction and $1-1.5 \%$ during maintenance) were secured in the stereotaxic apparatus (David Kopf Instruments, Tujunga, CA, USA) and the skull leveled between bregma and lambda. Bipolar stimulating electrodes (\#MS303 twisted stainless steel, outer diameter $125 \mu \mathrm{m}$, Plastics One, Roanoke, VA, USA) were implanted bilaterally into the lateral hypothalamic area (anteroposterior: -2.28 , mediolateral: \pm 2.7 , dorsoventral: $-8.5 \mathrm{~mm}$ from skull surface). Electrodes were implanted with a 70 angle to allow enough room to attach the stimulating cords on both sides. Electrodes were secured to the skull using dental cement and three screws. Animals were closely observed over 5 days post surgery. Animals with any neurological signs of brain damage were excluded from the study.

\section{Mania-induction procedure}

All the procedures took place in the early light phase between $0600 \mathrm{~h}$ and $0800 \mathrm{~h}$ during mania-induction days. The animal was placed individually into a clear Plexiglas cage $\left(12^{\prime \prime} \times 12^{\prime \prime} \times 30^{\prime \prime}\right.$, with ordinary bedding and food pellets on the floor) for $30 \mathrm{~min}$ at the beginning of the experiment to habituate to the new environment. This interval was called the pre-kindling interval and was followed by $60 \mathrm{~min}$ of kindling using the following stimulation parameters: bipolar configuration, $180 \mathrm{~Hz} \mathrm{~s}^{-1}$ frequency, $200 \mu \mathrm{s}$ pulse width and 10-s pulse durations followed by $30 \mathrm{~s}$ of rest. Seven trains were applied, each consisting of 10 pairings of 10-s duration stimulation pulses alternating with $30 \mathrm{~s}$ of rest, and $2 \mathrm{~min}$ of rest were allowed between trains. Stimulation amplitude was started at $1 \mathrm{~V}$ and was increased to $2 \mathrm{~V}$ for the rest of the stimulation trains. The reason we used only $1-2 \mathrm{~V}$ and did not escalate stimulation amplitude to $7 \mathrm{~V}$ as we have done in the first experiment is that we wanted to observe phenotypic differences between males and females at lower stimulation threshold and using higher amplitude could mask these subtle differences by giving a celling effect. Following all the seven kindling trains, the animal was kept in the observation chamber for 30 more minutes as post-kindling interval. Subsequently, the stimulating cord was disconnected and the animal was returned back to the home cage. The exact same procedure was repeated for five consecutive days. We used 5 days to span throughout the average cycle length, which typically lasts $4-5$ days $^{25}$ to avoid the confounding of hormonal variability during the estrous cycle phases. Furthermore, kindling-induced manic-like behavior is, by itself a stressor that could potentially perturb the hypothalamic-pituitary gonadal axis function as evident by abnormal gonadal hormone levels during mania. ${ }^{51,52}$

\section{Monitoring and quantifying behaviors during the process of mania-induction}

Continuous video recording of behaviors was performed over the 2-h mania-induction session. Recorded video files were transferred and stored in two separate external hard drives. Each animal recording was reviewed independently and behaviors were coded separately by two trained masked raters (UMC and NAG), and target behaviors were reviewed by the principal investigator of the study (OAA). The four primary behaviors were coded: (1) sexual behavior: the duration (in 5-s increments) of any oral contact with the genital area or immediate perigenital area or darting in female rats (Supplementary Videos S1, S2, S3); (2) rearing behavior: the number of episodes of standing on the two hind limbs for more than 5-s duration (Supplementary Video S4); (3) grooming behavior: the total time (in 5-s increments) of repeated mouthing of any body part except the genital and perigenital areas or repeated movement of the fore or hind paws over the snout, face, head, trunk or tail (Supplementary Video S5); and (4) feeding behavior: the duration (in 5-s increments) where the animal is observed holding and chewing food pellets. Chewing without food or chewing bedding was not considered feeding behavior (Supplementary Video S6).

24-hour sleep-wake cycle and locomotor activity monitoring in home cage during baseline, mania-induction and post-mania days Circadian locomotor activity counts in home cage were recorded using an infrared motion detector interfaced with a computerized data acquisition system (ClockLab, ActiMetrics, Wilmette, IL, USA) and later analyzed using MATLAB (The MathWorks, Natick, MA, USA). Total locomotor activity counts (bout analysis) and total activity time for light and dark phases were measured separately for each day of the experiment during baseline, mania-induction days and post-mania days. The nonactivity time was calculated by subtracting total activity time (minutes) from $720 \mathrm{~min}$ (12-h light/dark phase). This outcome measure was used as a surrogate marker for rest or sleep.

Voluntary ethanol consumption via two-bottle choice paradigm The animals were offered $20 \%(\mathrm{v} / \mathrm{v})$ ethanol vs tap water in a two-bottle choice paradigm throughout the experiment. Ethanol and water consumption were measured by weighing the animal and the two bottles daily. The amount of ethanol and water consumed were determined by subtracting the bottle weights from their initial weight. To avoid the confounding of side preference, we switched the bottle side every time fluid measurements were taken.

\section{Euthanasia and brain histology for verification of electrode tip location}

The animals were lightly anesthetized in a $\mathrm{CO}_{2}$ chamber and euthanized by rapid decapitation. The brain was carefully collected and fixed in paraformaldehyde solution for $24 \mathrm{~h}$ followed by $30 \%$ sucrose solution for 1 week, then covered with optimal cooling temperature compound for cryostat sectioning (Ted Pella, Redding, CA, USA) and stored at $-80^{\circ} \mathrm{C}$ until histology was performed. The brains were sectioned on a cryostat $(50 \mu \mathrm{m})$ and stained with hematoxylin and eosin. Verification of electrode tip location was done according to the atlas of Paxinos and Watson. ${ }^{53}$ (Electrode location is illustrated in Figure $1 \mathrm{~b}$ ).

\section{Statistical analysis}

Behavioral variables were presented as means \pm s.e.m. Four manic-like behaviors (duration of sexual, grooming and feeding behaviors, and frequency of rearing behavior) were quantified at three time intervals (prekindling, kindling and post-kindling) during each day of the five maniainduction days and summed together. Ethanol drinking $\left(\mathrm{g} \mathrm{kg}^{-1}\right.$ per day) and locomotor activity (counts per day) were also presented as means $\pm \mathrm{s}$. e.m and summed into three time intervals (baseline days, mania-induction days and post-mania-induction days). To correct for potential individual variability at baseline, we calculated behavioral changes from baseline to kindling (or mania induction) and to post-kindling (or post-mania), then we used a repeated measures analysis of variance (ANOVA) to examine for differences between males and females in individual behavioral manifestations during each time interval. Pearson correlation was performed to examine for potential relationship between the amount of ethanol $\left(\mathrm{g} \mathrm{kg}^{-1}\right.$ per day) consumed during the mania-induction days and locomotor activity counts. When a significant interaction was found, a post hoc testing was performed to determine pair-wise differences. Results were considered significant where $P<0.05$.

\section{RESULTS}

Phenotypic differences in LHK-induced sexual and rearing behaviors between male and female rats

During the surgical procedure, five animals (two males and three females) were excluded due to electrode location outside target area $(n=2)$ or pulling stimulating electrode $(n=2)$ or dying during surgery ( $n=1$ ) among 24 animals ( 12 males and 12 females) used in this experiment. Analysis of LHK-induced mania-like behaviors revealed notable sex differences in rearing behaviors, whereas no differences were found in sexual, grooming and feeding behaviors. For sexual behavior (Figure 2a), male rats showed a nonsignificant trend toward increased sexual behavior compared with female rats. Repeated measures ANOVA yielded a trend towards a main effect of sex $\left(F_{1,18}=4.34, P=0.0516\right)$, but not kindling $\left(F_{1,18}=0.99, P=0.33\right)$ nor interaction $\left(F_{1,18}=2.1, P=0.16\right)$.

Since the rearing behavior is correlated with manic-like behaviors, ${ }^{54,55}$ we measured a number of episodes of standing on the two hind limbs for more than $5 \mathrm{~s}$ (Figure 2b). The change in the frequency of rearing behavior from pre-kindling to kindling and post-kindling showed significant main effect of kindling $\left(F_{1,20}\right.$ $=12.15, P=0.002)$, sex $\left(F_{1,20}=9.74, P=0.005\right)$, but not interaction $\left(F_{1,20}=1.86, \quad P=0.18\right)$. Compared with males, females had 
a

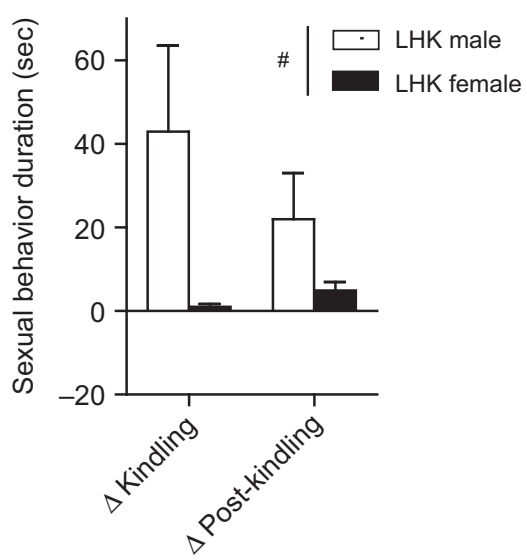

C



b
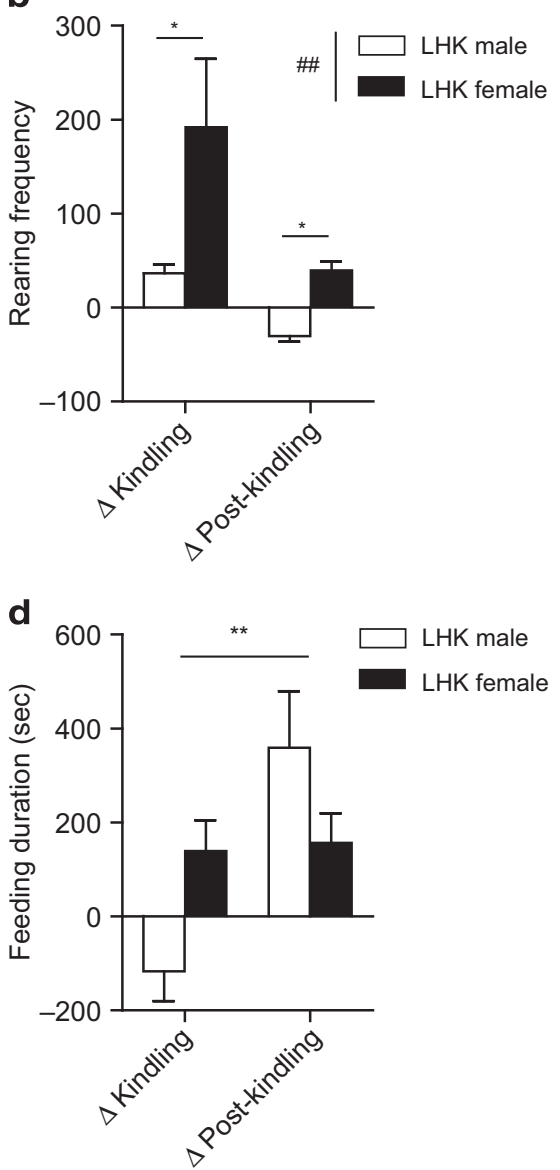

Figure 2. Change in manic-like behaviors: from the pre-kindling to kindling ( $\Delta$ kindling) and post-kindling ( $\Delta$ post-kindling) were compared between LHK male and female rats. (a) A nonsignificant trend towards a main effect of sex $\left(F_{1,18}=4.34,{ }^{\#} P=0.0516\right)$ was observed in the duration of sexual behavior, and significant main effects of kindling $\left(F_{1,20}=12.15,{ }^{*} P=0.002\right)$ and sex $\left(F_{1,20}=9.74,{ }^{\# \#} P=0.005\right)$ were evident in rearing behavior (b), whereas no significant effect for kindling or sex were detected in grooming behavior (c). However, a significant main effect of kindling $\left(F_{1,20}=6.13,{ }^{* *} P=0.02\right)$ and an interaction between kindling and sex $\left(F_{1,20}=5.29, P=0.03\right)$ were evident in the duration of feeding behavior (d) by repeated measures ANOVA. ${ }^{*} P<0.05$ by Tukey post hoc test; $n=9-10$ per rat type. Data are expressed as mean \pm s.e.m. ANOVA, analysis of variance; LHK, lateral hypothalamus kindled.

significantly more rearing during kindling (males vs females: $36.5 \pm 9.2$ vs $192.0 \pm 72.6$ ) and post-kindling (males vs females: $-30.2 \pm 6.0$ vs $39.4 \pm 9.8$ ).

We observed no significant effect of sex $\left(F_{1,20}=1.71, P=0.2\right)$, kindling $\left(F_{1,20}=2.67, P=0.1\right)$ or an interaction between the two factors $\left(F_{1,20}=2.44, P=0.1\right)$ on the duration of grooming behavior by repeated measures ANOVA (Figure $2 \mathrm{C}$ ). However, a significant main effect of kindling $\left(F_{1,20}=6.13, P=0.02\right)$, but not sexes $\left(F_{1,20}\right.$ $=0.15, P=0.7)$, with a significant interaction between kindling and sex $\left(F_{1,20}=5.29, P=0.03\right)$ was evident in the duration of feeding behavior (Figure $2 \mathrm{~d}$ ), suggesting that during the mania-induction phase, male rats may have suppressed appetite, which is consistent with clinical reports. ${ }^{56}$ However, further experiments are needed to explore this speculation as we only measured food intake during mania induction.

LHK female rats consume significantly more ethanol compared with LHK male rats

Next, we examined whether LHK-induced mania promote alcohol consumption as it is well known that mania increases a risk of alcohol abuse or binge alcohol consumption. ${ }^{11}$ Interestingly, female rats consumed significantly more ethanol compared with male rats during the mania (Figure 3). Repeated measures ANOVA on the dependent variable ethanol drinking revealed significant

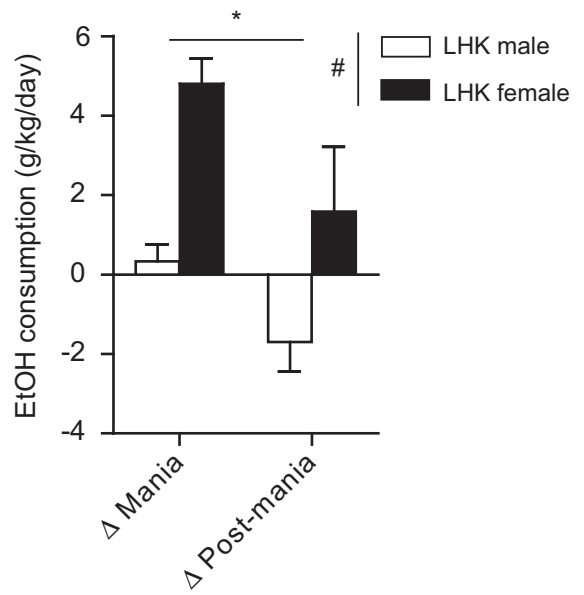

Figure 3. Ethanol (EtOH) consumption $\left(\mathrm{g} \mathrm{kg}^{-1}\right.$ per day) showed significant main effect for kindling $\left(F_{1,17}=4.93, " P=0.04\right)$ and sex $\left(F_{1,17}=10.79,{ }^{\#} P=0.004\right)$ by repeated measures ANOVA. ${ }^{*} P<0.05$ by Tukey post hoc test; $n=9-10$ per rat type. Data are expressed as mean \pm s.e.m. ANOVA, analysis of variance; LHK, lateral hypothalamus kindled. 
a

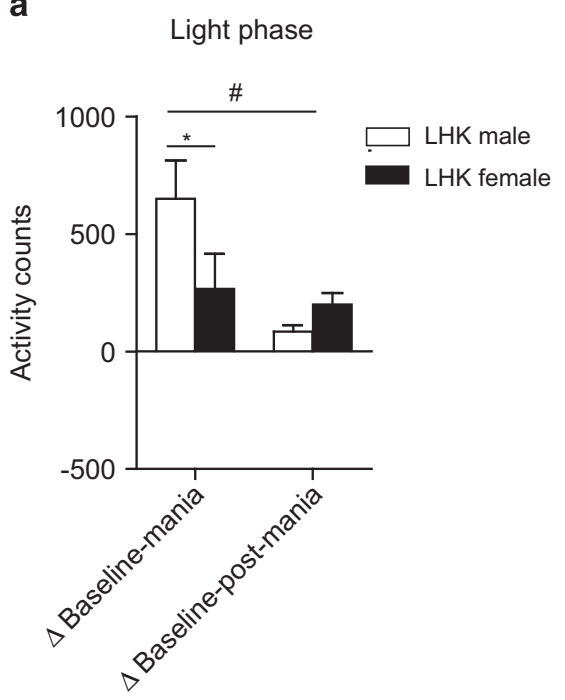

c Light phase

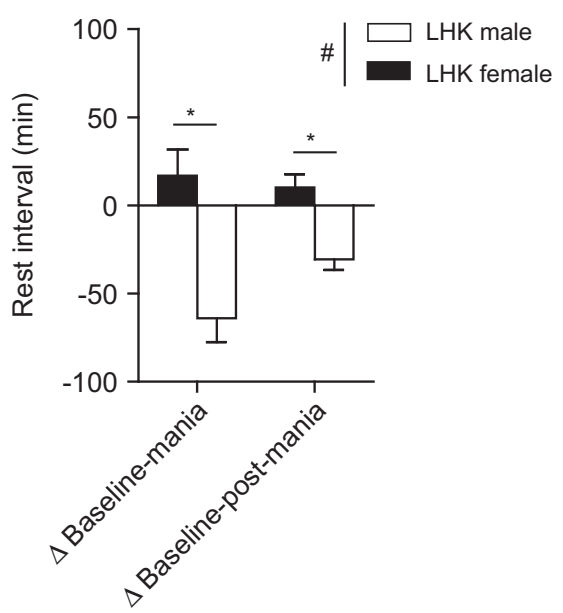

b

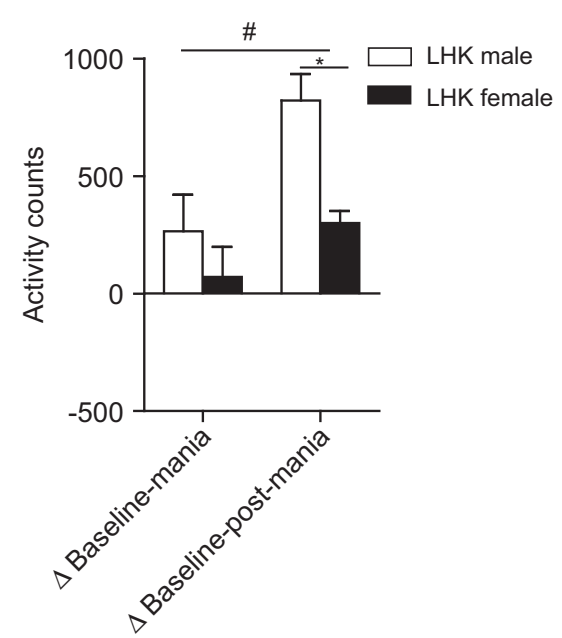

d



Figure 4. Changes in circadian locomotor activity counts from baseline to mania-induction days ( $\Delta$ mania) and to post-mania-induction days $(\Delta$ post-mania) were compared between LHK male and female rats in both the light and dark phases. (a) Shows changes in light phase activity counts. Significant main effect for mania induction $\left(F_{1,12}=12.56,{ }^{*} P=0.004\right)$ and an interaction between mania induction and sex $\left(F_{112}=7.82\right.$, $\left.{ }^{\#} P=0.01\right)$ were evident. The changes in dark-phase activity counts (b) show significant main effect of mania induction $\left(F_{1,14}=11.89,{ }^{\prime \prime} P=0.003\right)$ and sex $\left(\mathrm{F}_{1,14}=9.85,{ }^{*} P=0.007\right)$. Changes in light-phase rest interval (c) showed significant effect of sex $\left(F_{1,14}=30.44,{ }^{\#} P<0.0001\right)$ with males exhibiting significantly less rest intervals during both mania induction $\left({ }^{*} P=0.01\right)$ and post-mania-induction days $\left({ }^{*} P=0.002\right)$. Dark-phase rest interval (d) showed significant effect of sex $\left(F_{1,14}=8.57,{ }^{\#} P=0.01\right)$ and mania induction $\left(F_{1,14}=14.02,{ }^{*} P=0.002\right)$, by two-way ANOVA; ${ }^{*} P<0.05$ by Tukey post hoc test; $n=9-10$ per rat type. Data are expressed as mean \pm s.e.m. ANOVA, analysis of variance; LHK, lateral hypothalamus kindled.

main effects for mania induction $\left(F_{1,17}=4.93, P=0.04\right)$ and sex $(F$ $1,17=10.79, P=0.004)$, but no interaction between the two factors $\left(F_{1,17}=0.25, P=0.62\right)$. Female rats drank significantly more ethanol than males during mania-induction days (males vs females: $0.3 \pm 0.4$ vs $4.7 \pm 0.6, \mathrm{~g} \mathrm{~kg}^{-1}$ per day, $P=0.002$ ) and a trend during post-mania-induction days (males vs females: $-1.7 \pm 0.7$ vs $1.5 \pm 1.6, \mathrm{~g} \mathrm{~kg}^{-1}$ per day, $P=0.08$ ).

LHK male rats exhibit more hyperactivity and reduced rest intervals than LHK female rats

As manic-like behaviors alter circadian patterns or dysregulated circadian can influence mania phenotype, ${ }^{57}$ we investigated if manic-like behaviors are altered in light and dark phases (Figure 4). Light phase activity counts had a significant main effect for mania induction $\left(F_{1,12}=12.56, P=0.004\right)$ in all animals without differences between male and female rats $\left(F_{1,12}=2.26\right.$,
$P=0.15)$ but with a significant interaction between mania induction and sex $\left(F_{1,12}=7.82, P=0.01\right)$ by repeated measures ANOVA. Males showed more change (from baseline) in light phase activity compared with females during mania-induction days: (males vs females: $649.9 \pm 163.4$ vs $225.2 \pm 93.79, P=0.04$ ), but not during post-mania-induction days (males vs females: $84.60 \pm 27.06$ vs $199.8 \pm 49.31, P=0.1$; Figure 4 a).

Similarly, the change in dark phase activity counts showed significant main effect of mania-induction $\left(F_{1,14}=11.89, P=0.003\right)$ and sex $\left(F_{1,14}=9.85, P=0.007\right)$ but not interaction between the two factors $\left(F_{1,14}=2.06, P=0.17\right)$. Males were significantly more active than females during post-mania-induction days (males vs females: $821.2 \pm 113.2$ vs $300.0 \pm 52.0, P=0.003$ ), but not during mania-induction days (males vs females: $264.9 \pm 155.0$ vs $70.7 \pm 127.3, P=0.2$; Figure $4 b$ ).

Light phase rest interval showed significant effect of sex $\left(F_{1,14}\right.$ $=30.44, P<0.0001)$, but not mania induction $\left(F_{1,14}=1.46, P=0.24\right)$ 
or interaction $\left(F_{1,14}=3.31, P=0.09\right)$. Males had significantly less rest intervals during both mania-induction (males vs females: $-64.0 \pm 13.5$ vs $16.9 \pm 14.7 \mathrm{~min}, P=0.01)$ and post-mania-induction days (males vs females: $84.6 \pm 27.0$ vs $10.2 \pm 7.4 \mathrm{~min}, P=0.002$; Figure $4 \mathrm{c})$. On the other hand, a significant effect of sex $\left(F_{1,14}\right.$ $=8.57, P=0.01)$ and mania-induction $\left(F_{1,14}=14.02, P=0.002\right)$ without interaction between the two factors $\left(F_{1,14}=3.22\right.$, $P=0.09$ ) was observed by repeated measures ANOVA in the dark phase. Males had significantly less rest intervals during postmania-induction days (males vs females: $-102.3 \pm 18.9$ vs $-14.5 \pm 7.2, P=0.002$ ), but not during mania-induction days (males vs females: $0.6 \pm 27.7$ vs $21.7 \pm 19.8, P=0.5$; Figure $4 d$ ).

\section{DISCUSSION}

Our findings demonstrate that in the LHK mania model, females exhibited similar manic-like behaviors to male rats with certain phenotypic differences in rearing behavior, ethanol consumption and locomotor activity and rest patterns. LHK female rats exhibited solicitation sexual behavior such as darting ${ }^{58}$ as well as active genital licking during kindling and post-kindling (Figure 2a and Supplementary Video S2).

Our results are in agreement with the very limited clinical data examining the sex differences in humans with bipolar disorder. $^{14,15,17}$ LHK males in our study exhibited a nonsignificant trend towards more sexual behavior than females during kindling and post-kindling. In addition, the sexual behavior in both males and females was not evoked by an interaction with a rat of the opposite sex. The display of sexual solicitation behavior by LHK females in the form of receptive posture, lordosis and darting, ${ }^{58}$ and in the absence of sexually active male is indicative of maximal sexual motivation. ${ }^{59}$ This behavioral aspect in the LHK female rat is reminiscent of hypersexuality in humans during a manic episode. Young et al. ${ }^{15}$ studied 149 acutely manic patients (Young Mania Rating Scale $\geqslant 20$ ) and examined sex differences in individual item scores. Males had significantly higher scores compared with females.

Importantly, the LHK female rat had significant increase in rearing behavior during kindling and post-kindling compared with male rats (Figure $2 \mathrm{~b}$ and Supplementary Video S4). Rearing behavior is considered a measure of active exploratory behavior. ${ }^{60}$ Change in rearing frequency has been considered a measure for manic-like behavior in animal models. ${ }^{54,55}$ Female Wistar rats generally display more rearing activity than males at baseline. ${ }^{61}$ To correct for this baseline difference, we compared the changes in rearing frequency rather than actual frequency between males and females.

Interestingly LHK males exhibited significantly more locomotor activity and reduced rest interval during the light phase compared with females (Figures $4 a$ and $c$ ). This is contrary to the normal behavior of female rats as more active than males. ${ }^{62}$ It is difficult to speculate the cause of the lesser increase in activity in LHK female rats; however, it may be related to the difference in the chronic mild stress evoked by the single housing condition between males and females (reviewed by Simpson and Kelly ${ }^{63}$ ) or perhaps by the differences in ethanol consumption.

Compared with LHK males, female rats consumed significantly more ethanol during mania-induction and post-mania days (Figure 3). To determine whether the reduced activity in LHK 'manic' females is related to their ethanol consumption, we performed a Pearson correlation between daily ethanol consumption and activity counts during mania-induction days. No significant correlation $(r=-0.246, P=0.4)$ was observed. This finding is consistent with the clinical reports. Strakowski et al. ${ }^{12}$ studied 41 acutely manic patients during first hospitalization and found that women were 6.4 times more likely to have a history of comorbid substance use disorder. Similarly, in our previous publication, $^{13}$ there was a small cohort $(n=27)$ of alcohol- treatment-seeking women with bipolar disorder. Women reported higher lifetime maximum number of drinks in $24 \mathrm{~h}(21 \pm 11.5)$ than men $(13.4 \pm 8.6)$. Along the same lines, Frye et al. ${ }^{11}$ compared the rates of 'lifetime alcoholism' in a bipolar sample with rates in the general population. The risk of having alcoholism was greater for women with bipolar disorder (odds ratio $=7.53$ ) than for men with bipolar disorder (odds ratio $=2.77$ ). It is important to mention that the prevalence of alcohol abuse or dependence is significantly higher in men compared with women, ${ }^{64}$ whereas naive Sprague Dawley female rats generally drink more ethanol. ${ }^{65,66,67}$ Female Wistar rats, on the other hand, were reported to drink less ethanol compared with male rats, ${ }^{68}$ which was attributed to a twofold higher hepatic alcohol dehydrogenase enzyme activity ${ }^{69}$ in the female Wistar rats. Clinically, a study in Ashkenazic Jewish American college students reported that individuals carrying an alcohol dehydrogenase enzyme allele $\left(A D H 1 B^{*} 2\right)$ that codes for an isoform that is one order of magnitude more active than that coded by the usual $A D H 1 B^{*} 1$ (ref. 70 ) are also protected against heavy alcohol use and alcoholism. ${ }^{71}$ No genetic vulnerability or risk alleles for alcoholism have been reported in bipolar patients.

Another way to understand the observed sex difference in mania phenotype is to relate it to sexual dimorphism in the hypothalamic structure (reviewed by Madeira and Lieberman ${ }^{72}$ ) and differences in dopamine levels and turnover in the hypothalamus of female rats. $^{73}$ However, regardless of the underlying mechanisms mediating the sex differences in mania, women with bipolar disorder face serious negative impact compared with men. ${ }^{74}$

We would like to acknowledge several limitations for this study. First, as with all animal models, our phenotype findings may not parallel reported gender differences in patients with bipolar disorder. Second, we used only lower stimulation amplitude $(1-2 \mathrm{~V})$ to induce manic-like behavior. Female rats are susceptible to amygdala kindling at lower stimulation threshold compared with male rats. ${ }^{75}$ Third, in our first report, ${ }^{38}$ manic-like behaviors were only elicited in LHK rats. Kindling of other brain regions such as the nucleus accumbens or infra-limbic cortex was not associated with the induction of manic-like behavior phenotype. For that reason, we only performed kindling of the lateral hypothalamus in this study. Finally, there is a small possibility of false positive results as we did not correct for multiple comparisons. Despite these limitations, our data provide further validity to the LHK rat as a potentially useful model to investigate the neurobiological basis for this intriguing phenomenon and highlight sex-specific manifestations that should be made in the diagnosis or in the development of individualized treatment options.

\section{CONFLICT OF INTEREST}

MAF has received grant support from AssureRx Health, Myriad, Pfizer, National Institute of Mental Health (RO1 MH079261), National Institute of Alcohol Abuse and Alcoholism (P20AA017830), Mayo Foundation; has been a consultant to Janssen Global Services, LLC, Mitsubishi Tanabe Pharma Corporation, Myriad, Sunovion and Teva Pharmaceuticals; has received CME/Travel Support/presentation from CME Outfitters and Sunovian. The remaining authors declare no conflict of interest.

\section{ACKNOWLEDGMENTS}

This work is supported by a grant support from NIH/NCRR CTSA KL2 (RR024151; OAA)

\section{AUTHOR CONTRIBUTIONS}

OAA conceived, designed and conducted all the experiments. OAA, NAG, KM and $C V$ performed the behavioral experiments. OAA designed the kindling parameters. UC, NAG and KM performed the behavioral coding during kindling. OAA, NAG, CV and D-SC performed the statistical analysis, prepared the figures and wrote the manuscript. All the authors contributed to reviewing and editing the manuscript. All the authors read and approved the final manuscript. 


\section{REFERENCES}

1 Bebbington P, Ramana R. The epidemiology of bipolar affective disorder. Soc Psychiatry Psychiatr Epidemiol 1995; 30: 279-292.

2 Grant BF, Stinson FS, Hasin DS, Dawson DA, Chou SP, Ruan WJ et al. Prevalence, correlates, and comorbidity of bipolar I disorder and axis I and II disorders: results from the National Epidemiologic Survey on Alcohol and Related Conditions. J Clin Psychiatry 2005; 66: 1205-1215.

3 Martinez-Ortega JM, Jurado D, Gutierrez-Rojas L, Molero P, Ramos MA, Gurpegui M. Stability of sex differences by diagnosis in psychiatric hospitalizations. Psychiatry Res 2012; 198: 161-163.

4 Akiskal HS, Hantouche EG, Bourgeois ML, Azorin JM, Sechter D, Allilaire JF et al. Gender, temperament, and the clinical picture in dysphoric mixed mania: findings from a French national study (EPIMAN). J Affect Disord 1998; 50: 175-186.

5 Baldessarini RJ, Tondo L, Visioli C. First-episode types in bipolar disorder: predictive associations with later illness. Acta Psychiatr Scand 2014; 129: 383-392.

6 Suppes T, Mintz J, McElroy SL, Altshuler LL, Kupka RW, Frye MA et al. Mixed hypomania in 908 patients with bipolar disorder evaluated prospectively in the Stanley Foundation Bipolar Treatment Network: a sex-specific phenomenon. Arch Gen Psychiatry 2005; 62: 1089-1096.

7 Miller S, Suppes T, Hellmann G, Frye M, McElroy S, Nolen W et al. Mixed depression in the Stanley Foundation Bipolar Treatment Network: prevalence rate and clinical correlates during naturalistic follow up. Biol Psychiatry 2014; 75: 1S-401S.

8 Altshuler LL, Kupka RW, Hellemann G, Frye MA, Sugar CA, McElroy SL et al. Gender and depressive symptoms in 711 patients with bipolar disorder evaluated prospectively in the Stanley Foundation bipolar treatment outcome network. Am J Psychiatry 2010; 167: 708-715.

9 Kupka RW, Luckenbaugh DA, Post RM, Suppes T, Altshuler LL, Keck PE Jr et al. Comparison of rapid-cycling and non-rapid-cycling bipolar disorder based on prospective mood ratings in 539 outpatients. Am J Psychiatry 2005; 162: 1273-1280.

10 Schneck CD, Miklowitz DJ, Calabrese JR, Allen MH, Thomas MR, Wisniewski SR et al. Phenomenology of rapid-cycling bipolar disorder: data from the first 500 participants in the Systematic Treatment Enhancement Program. Am J Psychiatry 2004; 161: 1902-1908.

11 Frye MA, Altshuler LL, McElroy SL, Suppes T, Keck PE, Denicoff $\mathrm{K}$ et al. Gender differences in prevalence, risk, and clinical correlates of alcoholism comorbidity in bipolar disorder. Am J Psychiatry 2003; 160: 883-889.

12 Strakowski SM, Tohen M, Stoll AL, Faedda GL, Goodwin DC. Comorbidity in mania at first hospitalization. Am J Psychiatry 1992; 149: 554-556.

13 Hall-Flavin DK, Schneekloth TD, Loukianova LL, Karpyak VM, Lesnick TG, Biernacka $\mathrm{JM}$ et al. Utilization of residential alcoholism treatment in bipolar disorder. Am J Addict 2011; 20: 40-44.

14 Kennedy N, Boydell J, Kalidindi S, Fearon P, Jones PB, van Os J et al. Gender differences in incidence and age at onset of mania and bipolar disorder over a 35year period in Camberwell, England. Am J Psychiatry 2005; 162: 257-262.

15 Young RC, Kiosses D, Heo M, Schulberg HC, Murphy C, Klimstra S et al. Age and ratings of manic psychopathology. Bipolar Disord 2007; 9: 301-304.

16 Diflorio A, Jones I. Is sex important? Gender differences in bipolar disorder. Int Rev Psychiatry 2010; 22: 437-452.

17 Kawa I, Carter JD, Joyce PR, Doughty CJ, Frampton CM, Wells JE et al. Gender differences in bipolar disorder: age of onset, course, comorbidity, and symptom presentation. Bipolar Disord 2005; 7: 119-125.

18 Bouret SG, Simerly RB. Minireview: leptin and development of hypothalamic feeding circuits. Endocrinology 2004; 145: 2621-2626.

19 Williams G, Bing C, Cai XJ, Harrold JA, King PJ, Liu XH. The hypothalamus and the control of energy homeostasis: different circuits, different purposes. Physiol Behav 2001; 74: 683-701.

20 Beauregard M, Levesque J, Bourgouin P. Neural correlates of conscious selfregulation of emotion. $J$ Neurosci 2001; 21: RC165.

21 Ferretti A, Caulo M, Del Gratta C, Di Matteo R, Merla A, Montorsi F et al. Dynamics of male sexual arousal: distinct components of brain activation revealed by fMRI. Neuroimage 2005; 26: 1086-1096.

22 Redoute J, Stoleru S, Gregoire MC, Costes N, Cinotti L, Lavenne F et al. Brain processing of visual sexual stimuli in human males. Hum Brain Mapp 2000; 11: 162-177.

23 Hamann S, Herman RA, Nolan CL, Wallen K. Men and women differ in amygdala response to visual sexual stimuli. Nat Neurosci 2004; 7: 411-416.

24 Mendlewicz J, Linkowski P. Hypothalamic functions, sleep and circadian rhythms in affective disorders. Adv Biochem Psychopharmacol 1987; 43: 221-236.

25 Butcher RL, Collins WE, Fugo NW. Plasma concentration of LH, FSH, prolactin progesterone and estradiol-17beta throughout the 4-day estrous cycle of the rat. Endocrinology 1974; 94: 1704-1708.

26 de Lecea L, Carter ME, Adamantidis A. Shining light on wakefulness and arousal. Biol Psychiatry 2012; 71: 1046-1052.
27 Bhadoria R, Watson D, Danson P, Ferrier IN, McAllister VI, Moore PB. Enlargement of the third ventricle in affective disorders. Indian J Psychiatry 2003; 45: 147-150.

28 Cousins DA, Moore PB, Watson S, Harrison L, Ferrier IN, Young AH et al. Pituitary volume and third ventricle width in euthymic patients with bipolar disorder. Psychoneuroendocrinology 2010; 35: 1074-1081.

29 Pearlson GD, Barta PE, Powers RE, Menon RR, Richards SS, Aylward EH et al. Ziskind-Somerfeld Research Award 1996. Medial and superior temporal gyral volumes and cerebral asymmetry in schizophrenia versus bipolar disorder. Biol Psychiatry 1997; 41: 1-14.

30 Strakowski SM, Wilson DR, Tohen M, Woods BT, Douglass AW, Stoll AL. Structural brain abnormalities in first-episode mania. Biol Psychiatry 1993; 33: 602-609.

31 Bielau H, Trubner K, Krell D, Agelink MW, Bernstein HG, Stauch R et al. Volume deficits of subcortical nuclei in mood disorders: a postmortem study. Eur Arch Psychiatry Clin Neurosci 2005; 255: 401-412.

32 Brisch R, Bernstein HG, Dobrowolny H, Krell D, Stauch R, Trubner K et al. A morphometric analysis of the septal nuclei in schizophrenia and affective disorders: reduced neuronal density in the lateral septal nucleus in bipolar disorder. Eur Arch Psychiatry Clin Neurosci 2011; 261: 47-58.

33 Arita K, Ikawa F, Kurisu K, Sumida M, Harada K, Uozumi T et al. The relationship between magnetic resonance imaging findings and clinical manifestations of hypothalamic hamartoma. J Neurosurg 1999; 91: 212-220.

34 Arita K, Kurisu K, Kiura Y, lida K, Otsubo H. Hypothalamic hamartoma. Neurol Med Chir (Tokyo) 2005; 45: 221-231.

35 Kruk MR. Ethology and pharmacology of hypothalamic aggression in the rat. Neurosci Biobehav Rev 1991; 15: 527-538.

36 Ettrup KS, Sorensen JC, Rodell A, Alstrup AK, Bjarkam CR. Hypothalamic deep brain stimulation influences autonomic and limbic circuitry involved in the regulation of aggression and cardiocerebrovascular control in the Gottingen minipig. Stereotact Funct Neurosurg 2012; 90: 281-291.

37 Lacan G, De Salles AA, Gorgulho AA, Krahl SE, Frighetto L, Behnke EJ et al. Modulation of food intake following deep brain stimulation of the ventromedial hypothalamus in the vervet monkey. Laboratory investigation. J Neurosurg 2008; 108: $336-342$.

38 Abulseoud OA, Camsari UM, Ruby CL, Mohamed K, Abdel Gawad N, Kasasbeh A et al. Lateral hypothalamic kindling induces manic-like behavior in rats: a novel animal model. Int J Bipolar Disord 2014; 2-7.

39 Post RM, Weiss SR. Sensitization, kindling, and anticonvulsants in mania. J Clin Psychiatry 1989, 50: 23-30.

40 Van den Pol AN. Lateral hypothalamic damage and body weight regulation: role of gender, diet, and lesion placement. Am J Physiol 1982; 242: R265-R274.

41 Winn P, Tarbuck A, Dunnett SB. Ibotenic acid lesions of the lateral hypothalamus: comparison with the electrolytic lesion syndrome. Neuroscience 1984; 12: 225-240.

42 da Silva RK, Saad WA, Renzi A, Menani JV, Camargo LA. Effect of lateral hypothalamus lesions on the water and salt intake, and sodium and urine excretion induced by activation of the median preoptic nucleus in conscious rats. $J$ Auton Nerv Syst 1995; 53: 195-204.

43 Brownley KA, Peat CM, La Via M, Bulik CM. Pharmacological approaches to the management of binge eating disorder. Drugs 2014; 75: 9-32.

44 McElroy SL, Kotwal R, Keck PE Jr. Comorbidity of eating disorders with bipolar disorder and treatment implications. Bipolar Disord 2006; 8: 686-695.

45 Strakowski SM, MeElroy SL, Keck PW Jr, West SA. The co-occurrence of mania with medical and other psychiatric disorders. Int J Psychiatry Med 1994; 24: 305-328.

46 Kalueff AV, Tuohimaa P. The grooming analysis algorithm discriminates between different levels of anxiety in rats: potential utility for neurobehavioural stress research. J Neurosci Methods 2005; 143: 169-177.

47 Kametani $\mathrm{H}$. Analysis of age-related changes in stress-induced grooming in the rat. Differential behavioral profile of adaptation to stress. Ann N Y Acad Sci 1988; 525: 101-113.

48 Daban C, Vieta E, Mackin P, Young AH. Hypothalamic-pituitary-adrenal axis and bipolar disorder. Psychiatr Clin North Am 2005; 28: 469-480.

49 Goes FS, McCusker MG, Bienvenu OJ, Mackinnon DF, Mondimore FM, Schweizer B et al. Co-morbid anxiety disorders in bipolar disorder and major depression: familial aggregation and clinical characteristics of co-morbid panic disorder, social phobia, specific phobia and obsessive-compulsive disorder. Psychol Med 2012; 42: 1449-1459.

50 Arnold LM. Gender differences in bipolar disorder. Psychiatr Clin North Am 2003; 26: 595-620.

51 Ozcan ME, Banoglu R. Gonadal hormones in schizophrenia and mood disorders. Eur Arch Psychiatry Clin Neurosci 2003; 253: 193-196.

52 Whalley $\mathrm{L}$ et al. Selective increase in plasma luteinising hormone concentrations in drug free young men with mania. Br Med J (Clin Res Ed) 1985; 290: 99-102.

53 Paxinos G, Watson C. The Rat Brain in StereotaxicCoordinates, Fourth Edition, Academic Press: San Diego, CA, USA, 1998. 
54 Shaltiel G, Mark S, Kofman O, Belmaker RH, Agam G. Effect of valproate derivatives on human brain myo-inositol-1-phosphate (MIP) synthase activity and amphetamine-induced rearing. Pharmacol Rep 2007; 59: 402-407.

55 el-Mallakh RS, Harrison LT, Li R, Changaris DG, Levy RS. An animal model for mania: preliminary results. Prog Neuropsychopharmacol Biol Psychiatry 1995; 19 955-962.

56 McElroy SL, Kotwal R, Keck PE Jr., Akiskal HS. Comorbidity of bipolar and eating disorders: distinct or related disorders with shared dysregulations? J Affect Disord 2005; 86: 107-127.

57 McClung CA. How might circadian rhythms control mood? Let me count the ways. Biol Psychiatry 2013; 74: 242-249.

58 Erskine MS. Solicitation behavior in the estrous female rat: a review. Horm Behav 1989; 23: 473-502.

59 Fadem BH, Barfield RJ, Whalen RE. Dose-response and time-response relationships between progesterone and the display of patterns of receptive and proceptive behavior in the female rat. Horm Behav 1979; 13: 40-48.

60 Alvarez EO, Banzan AM. Functional lateralization of the baso-lateral amygdala neural circuits modulating the motivated exploratory behaviour in rats: role of histamine. Behav Brain Res 2011; 218: 158-164.

61 Dalla C, Antoniou K, Drossopoulou G, Xagoraris M, Kokras N, Sfikakis A et al. Chronic mild stress impact: are females more vulnerable? Neuroscience 2005; 135 703-714.

62 Field EF, Pellis SM. The brain as the engine of sex differences in the organization of movement in rats. Arch Sex Behav 2008; 37: 30-42.

63 Simpson J, Kelly JP. An investigation of whether there are sex differences in certain behavioural and neurochemical parameters in the rat. Behav Brain Res 2012; 229: 289-300.

64 Grant BF, Stinson FS, Dawson DA, Chou SP, Dufour MC, Compton W et al. Prevalence and co-occurrence of substance use disorders and independent mood and anxiety disorders: results from the National Epidemiologic Survey on Alcohol and Related Conditions. Arch Gen Psychiatry 2004; 61: 807-816.

65 Lancaster FE, Spiegel KS. Sex differences in pattern of drinking. Alcohol 1992; 9 415-420.

66 Lancaster FE. Sex differences in voluntary drinking by Long Evans rats following early stress. Alcohol Clin Exp Res 1998; 22: 830-836.
67 Juarez J, Barrios de Tomasi E. Sex differences in alcohol drinking patterns during forced and voluntary consumption in rats. Alcohol 1999; 19: 15-22.

68 Quintanilla ME, Tampier L, Sapag A, Gerdtzen Z, Israel Y. Sex differences, alcohol dehydrogenase, acetaldehyde burst, and aversion to ethanol in the rat: a systems perspective. Am J Physiol Endocrinol Metab 2007; 293: E531-E537.

69 Simon FR, Fortune J, Iwahashi M, Sutherland E. Sexual dimorphic expression of $\mathrm{ADH}$ in rat liver: importance of the hypothalamic-pituitary-liver axis. Am J Physiol Gastrointest Liver Physiol 2002; 283: G646-G655.

70 Hurley TD, Edenberg HJ, Bosron WF. Expression and kinetic characterization of variants of human beta 1 beta 1 alcohol dehydrogenase containing substitutions at amino acid 47. J Biol Chem 1990; 265: 16366-16372.

71 Shea SH, Wall TL, Carr LG, Li TK. ADH2 and alcohol-related phenotypes in Ashkenazic Jewish American college students. Behav Genet 2001; 31: 231-239.

72 Madeira MD, Lieberman AR. Sexual dimorphism in the mammalian limbic system. Prog Neurobiol 1995; 45: 275-333.

73 Dalla C, Antoniou K, Kokras N, Drossopoulou G, Papathanasiou G, Bekris S et al. Sex differences in the effects of two stress paradigms on dopaminergic neurotransmission. Physiol Behav 2008; 93: 595-605.

74 Osby U, Brandt L, Correia N, Ekbom A, Sparen P. Excess mortality in bipolar and unipolar disorder in Sweden. Arch Gen Psychiatry 2001; 58: 844-850.

75 Borowicz KK, Kleinrok Z, Czuczwar SJ. Influence of sex hormone antagonists on the anticonvulsant action of conventional antiepileptic drugs against amygdalakindled seizures in male and female rats. Eur Neuropsychopharmacol 2003; 13: 257-265.

(i) This work is licensed under a Creative Commons Attribution 4.0 International License. The images or other third party material in this article are included in the article's Creative Commons license, unless indicated otherwise in the credit line; if the material is not included under the Creative Commons license, users will need to obtain permission from the license holder to reproduce the material. To view a copy of this license, visit http://creativecommons.org/licenses/ by/4.0/

Supplementary Information accompanies the paper on the Translational Psychiatry website (http://www.nature.com/tp) 